\title{
Prevalence and phenotypic characterization of Enterococcus spp. isolated from food in Brazil
}

\author{
Carlos Henrique Camargo ${ }^{1,2}$, Ariane Bruder-Nascimento ${ }^{1}$, Sarah Hwa In Lee ${ }^{3}$, \\ Ary Fernandes Júnior ${ }^{1}$, Ramon Kaneno ${ }^{1}$, Vera Lúcia Mores Rall ${ }^{1}$ \\ ${ }^{1}$ Departamento de Microbiologia e Imunologia, Instituto de Biociências de Botucatu, \\ Universidade Estadual Paulista "Júlio de Mesquita Filho", Botucatu, SP, Brazil. \\ ${ }^{2}$ Departamento de Clínica Médica, Faculdade de Medicina de Botucatu, \\ Universidade Estadual Paulista "Júlio de Mesquita Filho", Botucatu, SP, Brazil. \\ ${ }^{3}$ Departamento de Engenharia de Alimentos, Faculdade de Zootecnia e Engenharia de Alimentos, \\ Universidade de São Paulo, Pirassununga, SP, Brazil.
}

Submitted: September 29, 2012; Approved: September 9, 2013.

\begin{abstract}
We evaluated the frequency of enterococci from food and found $95.2 \%$ of positivity, being $E$. faecium and E. faecalis the most frequent species. High-level streptomycin resistance was observed, as well as gelatinase and hemolysis activity, showing the potential role of environmental strains as reservoir of virulence and resistance traits.
\end{abstract}

Key words: Enterococcus spp., food, antimicrobial resistance.

Enterococci are lactic acid bacteria and although this genus comprises more than 25 species, E. faecium and $E$. faecalis are the main species isolated from food (Giraffa, 2002; Foulquié Moreno et al., 2006) and clinical samples (Cetinkaya et al., 2000). These bacteria can also be used as starter in the food industry due to their capacity to produce lipase, protease and volatile compounds ensuring desirable organoleptic features in some specific kinds of food. Despite their importance in food technology, certain features, such as the ability to growth over a wide range of temperature, salinity and $\mathrm{pH}$ make these organisms able to multiply in several foods and even spoil them (Giraffa, 2002; Foulquié Moreno et al., 2006).

Enterococcus have already been isolated from several kinds of food, such as vegetables, meat, milk and dairy foods (Giraffa, 2002; Hayes et al., 2003; Foulquié Moreno et al., 2006; Gomes et al., 2008). The frequency of isolation ranged from 52.5 to $99 \%$ (Hayes et al., 2003; Johnston and Jaykus, 2004; Gomes et al., 2008), depending on the kind of food, as well as the seasonal and manufacture conditions during their processing. The later aspects influence the bacterial survival, especially on cheese manufacturing and ripening (Foulquié Moreno et al., 2006).
Besides the high prevalence in food, several virulence factors and antimicrobial resistance have been identified in these enterococci (Franz et al., 2001; Barbosa et al., 2010).

The presence of virulence and resistance factors in enterococci is quite variable (Jett et al., 1994; Mundy et al., 2000) and the occurrence of these bacteria in food is a matter of debate (Franz et al., 2003). Differentiation between safe and non-safe strains is not easy, due to their capacity to exchange genetic elements with each other (Eaton and Gasson, 2001; Messi et al., 2006). The real role of virulence and antimicrobial resistance factors of food enterococci is not well elucidate, but bacteria presenting such factors in the environment may be understood as a genetic reservoir of virulence (Hayes et al., 2003). In this study we aimed to isolate enterococci species from different kinds of food evaluating some virulence factors and antimicrobial resistance.

We analyzed samples of poultry (35), pork (20), cheese (35) and vegetables (15) commercially available in eight supermarkets located in Botucatu, SP, Brazil. Samples were allocated in sterile plastic bags and transported in isothermal box under refrigeration during the way to the laboratory to be processed at the same day. Twenty-five

Send correspondence to C.H. Camargo. Departamento de Microbiologia e Imunologia, Instituto de Biociências de Botucatu, Universidade Estadual Paulista “Júlio de Mesquita Filho”, 18618-970 Botucatu, SP, Brazil. E-mail: chcamargo@fmb.unesp.br. 
grams of each sample was homogenized in $225 \mathrm{~mL}$ of bile esculin azide broth (BBL) in Stomacher Lab Blender 400 for $30 \mathrm{~s}$. Next, 0.1 and $0.01 \mathrm{~mL}$ of the initial dilution were spread onto the surface of bile esculin azide agar plates (BBL) and incubated at $45^{\circ} \mathrm{C} / 24$ and $48 \mathrm{~h}$. The initial dilutions were also incubated at $45^{\circ} \mathrm{C} / 48 \mathrm{~h}$, and a loop of the broth was streaked onto the surface of bile esculin azide agar plates, followed by incubation at $45^{\circ} \mathrm{C} / 24$ and $48 \mathrm{~h}$ (Hayes et al., 2003). In order to guarantee the absence of contamination, typical enterococci colonies (black) on bile esculine azide agar (from either direct growth or after the enrichment step) were streaked onto blood agar (Oxoid) plates prepared with $5 \%$ of defibrinated sheep blood and incubated at $37{ }^{\circ} \mathrm{C} / 24$ and $48 \mathrm{~h}$.

Identification of presumptive enterococci was confirmed using the tests proposed by Facklam et al. (2007): Gram staining, hemolysins, catalase, salt tolerance, esculin hydrolysis, pyrrolidonyl arylamidase (PYR), arginine decarboxylation, mannitol, arabinose, sorbitol and rafinose fermentation, pigment production, motility and tetrazolium reduction test. For determination of virulence traits, hemolysins were detected in blood agar base plates with $5 \%$ of defibrinated sheep blood after incubation at $37^{\circ} \mathrm{C} / 24 \mathrm{~h}$ and $5{ }^{\circ} \mathrm{C} / 48$ h. $\alpha$-Hemolysis was defined by the presence of a viridant halo around isolate colonies, while $\beta$-hemolysis was defined by translucent halo. Gelatinase assay was carried out as described by $\mathrm{Su}$ et al. (1991). Briefly, a spot of freshly cultured enterococci was seeded onto the surface of gelatin agar and the plate was incubated at $37^{\circ} \mathrm{C} / 48 \mathrm{~h}$; next the Petri dishes were kept at $4{ }^{\circ} \mathrm{C} / 4 \mathrm{~h}$, and a precipitation halo around the spot denoted a positive result. For antimicrobial susceptibility testing, vancomycin and high-level aminoglycoside (gentamicin and streptomycin) resistance was screened by disk diffusion assay $(120-\mu \mathrm{g}$ gentamicin disk and $300-\mu \mathrm{g}$ streptomycin disk) assay and confirmed by minimal inhibitory concentration (MIC) determined by agar dilution (MIC above 500 and $2000 \mu \mathrm{g} / \mathrm{mL}$ for gentamicin and streptomycin, respectively). Based on halos and MIC measures, the isolates were categorized as susceptible, intermediate and resistant according to the Clinical and Laboratory Standards Institute (2011). Categorical variables were compared by chi-square or Fisher's exact tests. Differences were considered statistically significant when $\mathrm{p} \leq 0.05$.

Hundred fifty-eight strains of enterococci were isolated from 100 samples out of 105 analyzed food samples (positivity ratio $=95.2 \%$ ). Enterococci was less frequently isolated from vegetable $(73.3 \%)$ than cheese $(100 \%)$, poultry $(100 \%)$ and pork $(95 \%)(p=0.001)$. Samples of all the eight evaluated supermarkets were positive. E. faecium was the most frequent species isolated (41.8\% of overall strains) followed by E. faecalis $(20.3 \%)$. Other species were also less frequently identified (Table 1).
Antimicrobial susceptibility showed that all of strains were susceptible to vancomycin and high-level gentamicin. Only two strains presented high-level streptomycin resistant (confirmed MIC $>2000 \mu \mathrm{g} / \mathrm{mL}$ ), both of them were identified as E. faecalis and isolated from poultry and pork meats purchased at the same supermarket, but with a gap of almost three months between the evaluation of two samples. Seventy-two percent of enterococci isolated from foods showed hemolysis; this characteristic was associated to $E$. faecium species $(\mathrm{p}=0.016)$. Gelatinase production, however, was associated with E. faecalis species $(\mathrm{p}<0.0001)$. More detailed data on source, frequencies and phenotypic characterization of enterococci strains are presented at Table 1.

In this study, enterococci were isolated from $95.2 \%$ of the 105 food samples. High frequency of enterococci in foods has also been previously reported in North America (Hayes et al., 2003; Johnston and Jaykus, 2004), Europe (Koluman, 2009), and Latin America (Morales et al., 2004). In Brazil, there is no much available information about it: Fracalanzza et al. (2007) analyzed 50 samples of meat and milk, and $86.6 \%$ of them were positive for enterococci. Later, Gomes et al. (2008) observed the presence of enterococci in 120 samples of raw and pasteurized cheese, meat, and vegetables and found out a lower frequency compared with our results ( $52.5 \%$ of positivity), probably due to the absence of an enrichment step.

We observed that E. faecalis and E. faecium together figured more than $60 \%$ of the overall isolated strains, but it is remarkable the diversity of species isolated from food samples (Table 1). Particularly E. haemoperoxidus (isolated from cheese, poultry, pork and lettuce samples) and $E$. sanguinicola (from cheese and poultry samples) species have rarely been recovered from food samples (Martín et al., 2009). Although more than 25 species have been described into Enterococcus genus, E. faecium and E. faecalis are the most widespread species isolated from food samples (Hayes et al., 2003, 2004; Abriouel et al., 2008; Gomes et al., 2008; Koluman, 2009). Our difficult to identify the species of a few strains was due to the similarity of phenotypic features; this limitation resulted in some isolates that have been only identified as "group" of strains according to Facklam et al. (2007) scheme. Hayes et al. (2004) have also had the same limitation to identify isolates from commercial poultry production environments.

In contrast with previous reports, including Brazilian studies (Fracalanzza et al., 2007; Gomes et al., 2008), E. casseliflavus and E. gallinarum were not found in our food samples. These species, and E. flavescens, exhibit intrinsic resistance to vancomycin mediate by the chromosomal gene vanC. For this reason, in the absence of a confirmatory PCR test, CLSI recommends that strains with intermediate inhibition halos for vancomycin $(15-16 \mathrm{~mm})$ should be submitted to vancomycin MIC, motility test and pigment production. Even though none of our isolates has shown values 
Table 1 - Prevalence, species frequency and distribution of virulence and resistance traits in Enterococcus spp. isolated from Brazilian foods.

\begin{tabular}{|c|c|c|c|c|c|c|c|c|}
\hline \multirow[t]{3}{*}{ Source $(\mathrm{n} / \%+)$} & \multirow[t]{3}{*}{ Species } & \multirow[t]{3}{*}{ Strains (n) } & \multicolumn{6}{|c|}{ Number (\%) of strains showing } \\
\hline & & & \multirow[t]{2}{*}{$\alpha$-Hemolysin } & \multirow[t]{2}{*}{$\beta$-Hemolysin } & \multirow[t]{2}{*}{ Gelatinase } & \multicolumn{3}{|c|}{ Resistance to } \\
\hline & & & & & & VAN & HLG & HLS \\
\hline Cheese & E. faecium & 29 & $28(96.6)$ & 0 & $1(3.4)$ & 0 & 0 & 0 \\
\hline \multirow[t]{4}{*}{$(35 / 100)^{\mathrm{a}}$} & Group 3 & 20 & $20(100.0)$ & 0 & 0 & 0 & 0 & 0 \\
\hline & E. haemoperoxidus & 3 & $3(100.0)$ & 0 & 0 & 0 & 0 & 0 \\
\hline & E. faecalis & 2 & $1(50.0)$ & 0 & $1(50.0)$ & 0 & 0 & 0 \\
\hline & E. sanguinicola & 1 & $1(100.0)$ & 0 & 0 & 0 & 0 & 0 \\
\hline Poultry & E. faecium & 19 & $12(63.2)$ & $1(5.3)$ & $5(26.3)$ & 0 & 0 & 0 \\
\hline \multirow[t]{7}{*}{$(35 / 100)^{\mathrm{a}}$} & E. faecalis & 15 & $2(13.3)$ & 0 & $12(80.0)$ & 0 & 0 & $1(6.7)$ \\
\hline & E. haemoperoxidus & 7 & $6(85.7)$ & 0 & $1(14.3)$ & 0 & 0 & 0 \\
\hline & Group 2* & 6 & $5(83.3)$ & 0 & $1(16.7)$ & 0 & 0 & 0 \\
\hline & E. sanguinicola & 6 & $4(66.6)$ & 0 & $1(16.7)$ & 0 & 0 & 0 \\
\hline & Group 3 & 4 & $4(100.0)$ & 0 & 0 & 0 & 0 & 0 \\
\hline & E. avium & 1 & $1(100.0)$ & 0 & 0 & 0 & 0 & 0 \\
\hline & Group 1 & 1 & 0 & $1(100.0)$ & 0 & 0 & 0 & 0 \\
\hline Vegetable & Group 3 & 5 & $5(100.0)$ & 0 & 0 & 0 & 0 & 0 \\
\hline \multirow[t]{5}{*}{$(15 / 73.3)^{\mathrm{b}}$} & E. faecalis & 3 & 0 & 0 & $2(66.7)$ & 0 & 0 & 0 \\
\hline & E. faecium & 3 & $3(100.0)$ & 0 & 0 & 0 & 0 & 0 \\
\hline & Group 5 & 1 & $1(100.0)$ & 0 & 0 & 0 & 0 & 0 \\
\hline & E. haemoperoxidus & 1 & $1(100.0)$ & 0 & 0 & 0 & 0 & 0 \\
\hline & E. collumbae/raffinosus & 1 & $1(100.0)$ & 0 & 0 & 0 & 0 & 0 \\
\hline Pork & E. faecium & 15 & $10(66.7)$ & 0 & $4(26.7)$ & 0 & 0 & 0 \\
\hline \multirow[t]{3}{*}{$(20 / 95.0)^{\mathrm{a}}$} & E. faecalis & 12 & $1(8.3)$ & 0 & $6(50.0)$ & 0 & 0 & $1(8.3)$ \\
\hline & Group 3 & 2 & $2(100.0)$ & 0 & 0 & 0 & 0 & 0 \\
\hline & E. haemoperoxidus & 1 & $1(100.0)$ & 0 & 0 & 0 & 0 & 0 \\
\hline All foods & E. faecium & 66 & $53(80.3)$ & $1(1.5)$ & $10(15.2)$ & 0 & 0 & $2(3.0)$ \\
\hline \multirow[t]{9}{*}{$(105 / 95.2)$} & E. faecalis & 32 & $4(12.5)$ & 0 & $21(65.6)$ & 0 & 0 & 0 \\
\hline & Group 3 & 31 & $31(100.0)$ & 0 & 0 & 0 & 0 & 0 \\
\hline & E. haemoperoxidus & 12 & $11(91.7)$ & 0 & $1(9.1)$ & 0 & 0 & 0 \\
\hline & E. sanguinicola & 7 & $5(71.4)$ & 0 & $1(14.3)$ & 0 & 0 & 0 \\
\hline & Group 2* & 6 & $5(83.3)$ & 0 & $1(16.7)$ & 0 & 0 & 0 \\
\hline & E. avium & 1 & $1(100.0)$ & 0 & 0 & 0 & 0 & 0 \\
\hline & E. collumbae/raffinosus & 1 & $1(100.0)$ & 0 & 0 & 0 & 0 & 0 \\
\hline & Group 1 & 1 & 0 & $1(100.0)$ & 0 & 0 & 0 & 0 \\
\hline & Group 5 & 1 & $1(100.0)$ & 0 & 0 & 0 & 0 & 0 \\
\hline All isolates & & 158 & $112(70.9)$ & $2(1.3)$ & $34(21.5)$ & 0 & 0 & $2(1.3)$ \\
\hline
\end{tabular}

a, b: different letters represent significant statistical differences $(\mathrm{p}=0.001)$.

VAN: vancomycin; HLG: High-level gentamicin [Minimal Inhibitory Concentration (MIC) $>500 \mu \mathrm{g} / \mathrm{mL}$ ]; HLS: High-level streptomycin (MIC $>2000$ $\mu \mathrm{g} / \mathrm{mL})$.

*: Other than E. casseliflavus and E. gallinarum, confirmed by absence of motility (hanging drop technique) (Facklam et al., 2007).

of inhibition halos lower than $17 \mathrm{~mm}$, the motility and pigment production tests were performed for all isolates. The strains presented neither motility nor pigment production, confirming the absence of E. casseliflavus and $E$. gallinarum in our samples.

Vancomycin resistance in enterococci isolated from food has a variable pattern both in Brazil and abroad (Franz et al., 2001; Giraffa, 2002; Johnston and Jaykus, 2004; Fracalanzza et al., 2007; Gomes et al., 2008). The source of vancomycin resistant strains appears to be different according to the geographic region where they emerge. In Europe it is attributed to the use of antimicrobial agents as growth promoter whereas in United States, it is attributed to the 
wide hospital usage of vancomycin (Woodford, 1998; Wegener et al., 1999).

The concern of high-level aminoglycoside resistance (HLAR) in enterococci is well documented. For instance, Donabedian et al. (2003) showed the transmission of HLAR strains among farm animals and humans. Although enterococci present intrinsic low level resistance to aminoglycosides, the association of high-levels of such drugs with a cell inhibitor antibiotic was showed to be efficient against enterococci in vivo (Murray, 1990). Resistance to high-level gentamicin (HLGR) and streptomycin (HLSR) was evaluated because HLGR predicts resistance to all aminoglycosides but streptomycin (Chow, 2000), which can be modified by other aminoglycoside acetyltransferase (Aac) family enzymes. By examining both aminoglycosides it is possible to predict high-level resistance to aminoglycosides (Chow, 2000; Clinical and Laboratory Standards Institute, 2011).

Resistance to high-level gentamicin was not observed, whereas only two (1.3\%) strains isolated from poultry and pork samples showed high-level streptomycin resistance. In previous reports, HLSR was also more frequent than HLGR (Franz et al., 2001; Johnston and Jaykus, 2004; Fracalanzza et al., 2007). In opposition, Teuber et al. (2009) found out $80 \%$ of enterococci isolated from cheese with high-level gentamicin resistance, and, in Brazil, Gomes et al. (2008) reported 22\% of E. faecalis with high-level gentamicin resistance. The low prevalence of HLAR we have observed may be explained by the fact that in Brazil, the use of antimicrobial agents was prohibited as growth promoters in farms (Brasil, 1998) until some years ago (Brasil, 2009).

Virulence markers are also cause of concern among enterococci from food (Eaton and Gasson, 2001; Foulquié Moreno et al., 2006). Several factors such as aggregation proteins to eukaryotic cells and adhesins, biofilm production, extracellular proteases (colagenases, gelatinase), cytolysins (bacteriocins and hemolysins), leukocytary evasion proteins and sex pheromones have been associated with enterococci pathogenicity (Jett et al., 1994; Eaton and Gasson, 2001). Hemolysin production seems to be associated with virulence in experimental models, as well as the gelatinase (Mundy et al., 2000) and the expression of these characteristics was associated with E. faecalis and $E$. faecium, according to previous study (Mundy et al., 2000).

In this study we observed higher frequency of $\alpha$-hemolysin $(79.8 \%)$ than $\beta$-hemolysin $(12.6 \%)$ in the food enterococci, in agreement with previous reports (Gomes et al., 2008; Barbosa et al., 2010). The gelatinase production was present in about $20 \%$ of the strains, most of them belonging to E. faecalis species. Most of these strains were isolated from chicken meat, diverging from Franz et al. (2001) that found a high incidence of gelatinase producing E. faecalis in cheese samples. It is remarkable that both foods are rich in protein contents and that gelatinase pro- ducing strains can use these substrata as amino acid source (Franz et al., 2001). In our samples, $65.6 \%$ of the $E$. faecalis strains were gelatinase producers, while $15.2 \%$ of the $E$. faecium strains showed this virulence factor. Gelatinaseproducing enterococci were isolated from meat and it could cause the food degradation (Gomes et al., 2008).

Several studies have investigated the occurrence of virulence factors and antimicrobial resistance in enterococci from different sources as environment, water, food and infectious diseases (Semedo et al., 2003). For instance, Abriouel et al. (2008) have found virulence traits both in clinical and food, water and soil isolated strains. In the same way, Eaton and Gasson (2001) found a higher proportion of virulent enterococci strains in clinical isolates compared with those isolated from food or employed as starter culture in the food industry. The starter culture should present proteases and lipases in order to metabolize volatile compounds while they should be free of virulence determinants (Foulquié Moreno et al., 2006). The concomitant presence of virulence factors in clinical and environmental samples, however, hinders the classification as safe or non-safe strains (Eaton and Gasson, 2001; Franz et al., 2001).

In summary, we observed the presence of Enterococcus spp. in almost all the samples evaluated as well as hemolysin and gelatinase production in those strains. Antimicrobial resistance was very rare. The remarkable finding of enterococci in foods is their ability to exchange virulence and drug resistance with potential pathogenic strains (Eaton and Gasson, 2001; Messi et al., 2006). It suggests us that environmental and food strains can represent a natural reservoir of these features, enhancing the development of more dangerous clinical strains.

\section{Acknowledgments}

The authors thank FAPESP for the scientific initiation fellowship to Carlos Henrique Camargo.

\section{References}

Abriouel H, Omar N, Molinos A, López R, Grande M, Martínez-Viedma P, Galvez A (2008) Comparative analysis of genetic diversity and incidence of virulence factors and antibiotic resistance among enterococcal populations from raw fruit and vegetable foods, water and soil, and clinical samples. Int J Food Microbiol 123:38-49.

Barbosa J, Gibbs PA, Teixeira P (2010) Virulence factors among enterococci isolated from traditional fermented meat products produced in the North of Portugal. Food Control 21:651-656.

Brasil (1998) Portaria $N^{o} 193$, de 12 de maio de 1998. Retrieved from

http://extranet.agricultura.gov.br/sislegis-consulta/consulta rLegislacao.do?operacao $=$ visualizar\&id $=1125$.

Brasil (2009) Instrução Normativa No 26, de 09 de julho de 2009. Retrieved

from 
http://extranet.agricultura.gov.br/sislegis-consulta/consulta rLegislacao.do?operacao=visualizar\&id $=20408$.

Cetinkaya Y, Falk P, Mayhall C (2000) Vancomycin-resistant enterococci. Clin Microbiol Rev 13:686-707.

Chow JW (2000) Aminoglycoside resistance in enterococci. Clin Infect Dis 31:586-589.

Clinical and Laboratory Standards Institute (2011) Performance standards for antimicrobial susceptibility testing: twenty first informational supplement. M100-S21. CLSI, Wayne.

Donabedian S, Thal L, Hershberger E, Perri M, Chow J, Bartlett P, Zervos M (2003) Molecular characterization of gentamicin-resistant Enterococci in the United States: evidence of spread from animals to humans through food. J Clin Microbiol 41:1109-1113.

Eaton T, Gasson M (2001) Molecular screening of Enterococcus virulence determinants and potential for genetic exchange between food and medical isolates. Appl Environ Microbiol 67:1628-1635.

Facklam RR, Carvalho MGS, Teixeira LM (2007) Enterococcus. In: Murray, P.R., Baron, E.J., Pfaller, M.A., Jorgensen J.H., Landry, M.L. (eds.) Manual of Clinical Microbiology. American Society for Microbiology, Washington, p. 430-442.

Foulquié Moreno M, Sarantinopoulos P, Tsakalidou E, De Vuyst L (2006) The role and application of enterococci in food and health. Int J Food Microbiol 106:1-24.

Fracalanzza S, Scheidegger E, Santos P, Leite P, Teixeira L (2007) Antimicrobial resistance profiles of enterococci isolated from poultry meat and pasteurized milk in Rio de Janeiro, Brazil. Mem Inst Oswaldo Cruz 102:853-859.

Franz C, Muscholl-Silberhorn A, Yousif N, Vancanneyt M, Swings J, Holzapfel W (2001) Incidence of virulence factors and antibiotic resistance among Enterococci isolated from food. Appl Environ Microbiol 67:4385-4389.

Franz C, Stiles M, Schleifer K, Holzapfel W (2003) Enterococci in foods - a conundrum for food safety. Int J Food Microbiol 88:105-122.

Giraffa G (2002) Enterococci from foods. FEMS Microbiol Rev 26:163-171.

Gomes B, Esteves C, Palazzo I, Darini A, Felis G, Sechi L, De Martinis E (2008) Prevalence and characterization of Enterococcus spp. isolated from Brazilian foods. Food Microbiol 25:668-675.

Hayes J, English L, Carr L, Wagner D, Joseph S (2004) Multiple-antibiotic resistance of Enterococcus spp. isolated from commercial poultry production environments. Appl Environ Microbiol 70:6005-6011.
Hayes J, English L, Carter P, Proescholdt T, Lee K, Wagner D, White D (2003) Prevalence and antimicrobial resistance of Enterococcus species isolated from retail meats. Appl Environ Microbiol 69:7153-7160.

Jett B, Huycke M, Gilmore M (1994) Virulence of enterococci. Clin Microbiol Rev 7:462-478.

Johnston L, Jaykus L (2004) Antimicrobial resistance of Enterococcus species isolated from produce. Appl Environ Microbiol 70:3133-3137.

Koluman A (2009) Occurrence and antimicrobial resistance of enterococci in retail foods. Food Control 20:281-283.

Martín B, Corominas L, Garriga M, Aymerich T (2009) Identification and tracing of Enterococcus spp. by RAPD-PCR in traditional fermented sausages and meat environment. J Appl Microbiol 106:66-77.

Messi P, Guerrieri E, de Niederhäusern S, Sabia C, Bondi M (2006) Vancomycin-resistant enterococci (VRE) in meat and environmental samples. Int J Food Microbiol 107:218222.

Morales G, Blanco L, Arias ML, Chaves C (2004) Evaluación de la calidad bacteriología de tilapia fresca (Orochoromis niloticus) proveniente de la zona norte de Costa Rica. Arch Latinoam Nutr 54:433-437.

Mundy L, Sahm D, Gilmore M (2000) Relationships between enterococcal virulence and antimicrobial resistance. Clin Microbiol Rev 13:513-522.

Murray B (1990) The life and times of the Enterococcus. Clin Microbiol Rev 3:46-65.

Semedo T, Santos M, Lopes M, Figueiredo Marques J, Barreto Crespo M, Tenreiro R (2003) Virulence factors in food, clinical and reference Enterococci: a common trait in the genus? Syst Appl Microbiol 26:13-22.

Su Y, Sulavik M, He P, Makinen K, Makinen P, Fiedler S, Clewell D (1991) Nucleotide sequence of the gelatinase gene ( $\mathrm{gel} \mathrm{E}$ ) from Enterococcus faecalis subsp. liquefaciens. Infect Immun 59:415-420.

Teuber M, Meile L, Schwarz F (1999) Acquired antibiotic resistance in lactic acid bacteria from food. Antonie Van Leeuwenhoek 76:115-137.

Wegener H, Aarestrup F, Jensen L, Hammerum A, Bager F (1999) Use of antimicrobial growth promoters in food animals and Enterococcus faecium resistance to therapeutic antimicrobial drugs in Europe. Emerg Infect Dis 5:329-335.

Woodford N (1998) Glycopeptide-resistant enterococci: a decade of experience. J Med Microbiol 47:849-862.

All the content of the journal, except where otherwise noted, is licensed under a Creative Commons License CC BY-NC. 